\title{
EDUCATION AND LEARNING
}

\section{Bringing the learning organisation to your workplace}

Howard Skinner

Postgrad Med J 2007;83:466-468. doi: 10.1136/pgmj.2006.054148

The article describes an educational intervention designed for a traditional primary health care team. The intervention consisted of a series of educational exercises designed to enhance team member self efficacy and provide experience of a variety of effective shared learning strategies. The primary health care team were then given the opportunity to apply this new knowledge and skills to designing their own teaching sessions as part of a practice teaching competition. The evaluative framework and feedback from the participants demonstrating achievement of the learning outcomes are then described.

$\mathrm{T}$ he multidisciplinary team is the key mode of delivery of primary care services in the UK, and shared learning between healthcare professionals in the National Health Service has been advocated as a means to improve the ability of individuals to work together in optimising patient outcomes. ${ }^{1}$ The ever-changing NHS necessitates an organisational flexibility that is not readily achieved using traditional hierarchical management structures in which professional roles are rigidly maintained. In 2000 Davies and Nutley's review highlighted Senge's concept of the learning organisation, a description of key elements to teams which can successfully adapt to a rapidly changing environment. ${ }^{2}$ Such teams tend to have an appreciation of mutual roles, promote personal development among the membership, learn together as teams, learn from success, constructively manage mistakes and are empowered with a shared goal and purpose. Such non-specific ideals can make the concept of a learning organisation seem distant and irrelevant. This paper describes a practical approach to bringing many of the key elements of the learning organisation into your own workplace.

\section{THE SETTING}

The intervention evaluated within this account involved two half-day workshops that sought to examine and enhance the interprofessional educational process (IPE) within a traditional semi-rural training practice. The practice serves 6700 with four general practitioners, three practice nurses, three district nurses and 10 members of the administrative team.

Correspondence to: Dr Howard Skinner, The Tutbury Practice, Monk Street, Tutbury,

Staffordshire DE13 9NA UK; hdskinner@doctors. org.uk

Received 2 October 2006 Accepted 2 October 2006

.........................

\section{LEARNING OUTCOMES}

- The participants would know some core educational theory relating to adult learning as individuals and in teams.

- The participants would be able to assess existing practice team teaching activities in the context of their individual learning plans.
- The participants would assess the value of a range of novel teaching-learning methodologies.

- The participants would have the opportunity to apply this new knowledge in designing, delivering and then assessing interprofessional teaching sessions. In so doing the participants would be encouraged from a hierarchical/dependent role in planning towards a cooperative and then autonomous planning mode (using Heron's Six Category Intervention Analysis model). ${ }^{3}$

- The participants would reflect upon these experiences and use them to create a plan for future practice team learning sessions.

\section{THE INTERVENTION}

The first half-day workshop was designed to use various micro-teaching exercises to empower members of a primary health care team with basic knowledge of adult educational principles derived from the work of Knowles and Brookfield. ${ }^{4}$ The workshop sought to empower the team through highlighting the relevance of prior knowledge and skills using a "round robin" exercise in which each team member was asked to describe something they were good at. These examples were used to provide personal empowerment through emphasising self-directed learning expertise in the group as well as the key elements of the general principles of adult learning and the Kolb's experiential learning cycle. ${ }^{6}$ Having established this core knowledge to facilitate educational dialogue within the primary health care team, the recommendations of Parsell and Bligh for effective IPE teaching interventions were presented (team ownership of the planning process, clear goals for session, inclusiveness, relevance, interactive methods, recognition of prior expertise, feedback provision, identification of learning resources and attention to gathering evaluation). The team members were then given the experience of defining and applying their own assessment criteria (as part of a self and peer assessment exercise) through a paper aeroplane-making competition. ${ }^{7}$ Throughout this workshop, arts materials were used to illustrate key themes as well as provide the staff with examples of materials that could be used for their own teaching session plans.

Following these educational opportunities the practice team were invited to apply their new knowledge in devising a multidisciplinary teaching session for the second half-day. The task set for two groups was to produce and deliver a $45 \mathrm{~min}$ teaching session for their colleagues on a topic relevant to the general practice team. The presentation must actively involve all the team 
members in some way and be relevant to primary care and inclusive for the primary health care team. The topic might be a straightforward clinical area or might involve learning across subject areas like dealing with bereavement, for example. The groups must consist of a minimum of one doctor, one nurse and one receptionist/manager/administrator. The groups were provided with seven assessment criteria for the session and told to generate seven more of their own. Each assessment criterion would be marked out of 10 (except inclusiveness which attracted 20 marks in order to highlight its importance for shared learning) by the audience. The criteria that the team were provided to the groups were based on the recommendations of Parsell and Bligh:

1. Evidence of clear aims for the session.

2. The session takes into account the prior skills/experience of the audience.

3. The session is inclusive of everyone in the audience-that is, it engages the whole team not just one group.

4. The session is interactive-that is, it gets the audience active.

5. The topic is relevant to primary care and the team.

6. There is evidence that any audience participation receives appropriate feedback.

7. The presentations' ability to change the way the team works.

Following the presentation of teaching sessions by the two multidisciplinary groups at the second workshop and subsequent self/peer assessment of criteria, feedback was provided to both groups about their sessions. Finally, the reunited practice team was encouraged to consider how the intervention would be used to guide future IPE within the practice.

\section{EVALUATING THE INTERVENTION}

The design of the evaluation for the intervention was multifaceted to reflect the fact that the educational intervention sought to influence the presage, the teaching-learning process and the outcome/product (Biggs' 3P model). ${ }^{8}$

Firstly, given the demanding nature of the first half-day workshop, a brief round robin exercise was used to gather practice team reaction (Kirkpatrick level 1). ${ }^{9}$ Following the teaching competition presentations, further evaluative information was gathered during a Pendleton-style formative appraisal process and subsequent discussion. ' In addition, participants were asked to self-rate their learning using a performative rating scale to measure the perceived progress towards each defined learning outcome for the intervention. Lastly, following the second workshop an evaluation form was distributed that sought to analyse a number of aspects of presage, process and outcome. ${ }^{8}$

The use of "feed-forward" evaluation material from the assessment materials together with the various team appraisal processes would demonstrate effectiveness of teaching through qualitative presentation of participant responses. In so doing, effectiveness in terms of outcome would be defined with reference to Biggs' standards model rather than the traditional quantitative measurement model. A positive outcome would therefore be demonstrated by presentation of materials that provided evidence of qualitative development by the learners. Through a combination of further evaluative methods it was hoped to provide a triangulation of sufficient qualitative evidence of significant positive impacts upon presage, process and outcome while avoiding unnecessary duplication and excessive enquiry of too many criteria. While this evaluative framework lacked the rigour and clarity of Tyler's predetermined objectives approach, it seemed well suited to the context, reinforced learner autonomy and was flexible to the type of unplanned learning that can occur in practice team settings.

\section{SO WAS THE INTERVENTION EFFECTIVE?}

Twenty members of the primary health care team participated in the first workshop and 13 volunteered to participate in the second workshop's team teaching competition. The intervening weeks between the first workshop and the competition became a hive of activity, with both groups striving for supremacy. Both teams met on a number of occasions outside of traditional opening hours to prepare for their sessions. In so doing the two teams adopted, quite spontaneously, two very different approaches to their task. The first group adopted a team ethos in which traditional roles were abandoned and members of the primary health care team deliberately took on roles from across the team. This first team produced an impressive film depicting a patient experiencing all manner of problems with communication from members of the primary care team. The remainder of the workshop provided a number of microteaching exercises to highlight key aspects to basic communication and then a second film demonstrated how the patient's journey might have been so much simpler if these communication principles had been followed. The second team featured slightly less experienced staff and in this team traditional professional roles were maintained. Team members each took a role and the teaching session followed a couple (played by two team members) going on a package holiday. As the couple were followed, periodically members of the team appeared to give brief commentary about the process of travel health and how the surgery provided services. The session was concluded by an interactive quiz to see how much the audience had learned.

Both teams therefore demonstrated a capacity for cooperative and even autonomous mode planning of teaching-learning activities. There was clear evidence from discussion both within and following the plenary session that the practice team as a whole had developed a far deeper appreciation of where interprofessional education fitted in with multi-professional educational events as well as uni-professional and individual activities. It became clear from evaluative feedback and discussion during the session that the practice team appreciated the value of collaborative exchange and role appreciation while also accepting that not all team events needed to be like this. The feedback received suggested that the first of the teaching competition groups seemed to have gained particular value from the exchange in roles that had occurred during their preparations. The whole practice team had clearly developed an appreciation for basic educational principles as evidenced by their presentations, their contributions to the Pendleton formative appraisal exercise, and the participative self-assessment process. Both teams were able to identify valued areas in which their presentations may have been improved and welcomed constructive feedback in areas of unconscious incompetence.

It was noteworthy that the teams generated several well defined assessment criteria for their sessions including the use of a variety of audio-visual media, evidence of session planning and evidence of improved self-rated knowledge/skills. The Pendleton formative appraisal exercise was positive with useful, well-received feedback provided to two receptive teams. Initially both teams seemed quite withdrawn and a little unwilling to contribute, but within 4-5 min each team seemed to appreciate the constructive feedback that they were receiving. As the wider group could see that the session was supportive and productive, they began to contribute to the feedback process. Even the more reserved (and occasionally cynical) members of the team accepted the process with 
enthusiasm and by the end of the session were contributing actively to the discussion. The teams certainly indicated a great enthusiasm to participate in planning and delivering future multi-professional sessions. Furthermore, a sizeable minority of team members spread across a number of professional disciplines indicated their commitment to producing a written educational philosophy for the practice.

\section{CONCLUSIONS}

The intervention described was relatively straightforward and easy to deliver to a traditional primary care team who quickly improved their knowledge of basic principles of successful shared learning before demonstrating proficiency in applying this knowledge. A similar package of intervention could be readily adapted for use with multidisciplinary teams in different contexts. Such an approach can have a powerful impact in promoting the breakdown of traditional hierarchies in organisations and facilitating flattened structures with considerably enhanced role appreciation across the multidisciplinary team. This is the foundation for the creation of a learning organisation.

Competing interests: the author is not aware of any competing interest

\section{REFERENCES}

1 Barr H. Interprofessional education today, yesterday and tomorrow. UK: Learning and Teaching Support Network for Health Sciences and Practice, Centre for Health Sciences and Practice, 2003.

2 Davies TO, Nutley S. Developing learning organisations in the new NHS. BMJ 2000;320:998-1001.

3 Heron J. The facilitator's handbook. London: Kogan Page, 1999.

4 Knowles M. Self-directed learning. New York: Association Press, 1975.

5 Brookfield, SD. Understanding and facilitating adult learning. Milton Keynes: Oxford University Press, 1986.

6 Kolb, D. Experiential learning. London: Prentice Hall, 1974

7 Parsell, G, Bligh, J. The development of a questionnaire to assess the readiness of health care students for interprofessional learning (RIPLS). Medical Education 1999;33:95-100.

8 Biggs J. Teaching for quality learning at university, 2nd ed. Maidenhead, Berkshire: Open University Press, 1999.

9 Mohanna K, Chambers R, Wall D, et al. Teaching made easy: a manual for health professionals, 2nd ed. Abingdon, Oxon: Raddliffe Medical Press, 2003.

\section{bmjupdates+}

bmiupdates+ is a unique and free alerting service, designed to keep you up to date with the medical literature that is truly important to your practice.

bmiupdates+ will alert you to important new research and will provide you with the best new evidence concerning important advances in health care, tailored to your medical interests and time demands.

Where does the information come from?

bmjupdates+ applies an expert critical appraisal filter to over 100 top medical journals A panel of over 2000 physicians find the few 'must read' studies for each area of clinical interest

Sign up to receive your tailored email alerts, searching access and more...

www.bmjupdates.com 